\title{
Chicken serum uric acid level is regulated by glucose transporter 9
}

\author{
Xuedong Ding ${ }^{1}$, Chenglu Peng ${ }^{1}$, Siting $\mathrm{Li}^{1}$, Manman $\mathrm{Li}^{1}$, Xinlu $\mathrm{Li}^{1}$, Zhi Wang ${ }^{1}$, \\ Yu Li ${ }^{1}$, Xichun Wang ${ }^{1}$, Jinchun $\mathrm{Li}^{1}{ }^{1 *}$, and Jinjie $\mathrm{Wu}^{1, *}$
}

\author{
* Corresponding Authors: \\ Jinchun Li \\ Tel: +86-18226607463, \\ Fax: +86-0551- 65786328, \\ E-mail: jinchunli64@163.com \\ Jinjie Wu \\ Tel: +86-13505514926, \\ Fax: +86-0551-65785484, \\ E-mail:wjj@ahau.edu.cn
}

${ }^{1}$ College of Animal Science and Technology, Anhui Agricultural University, Hefei 230036, China

\section{ORCID}

Xuedong Ding

https://orcid.org/0000-0002-1873-8711 Chenglu Peng

https://orcid.org/0000-0003-0084-0520

Siting Li

https://orcid.org/0000-0002-8292-1393 Manman Li

https://orcid.org/0000-0003-0188-826X Xinlu Li

https://orcid.org/0000-0003-3482-0587

Zhi Wang

https://orcid.org/0000-0001-7501-4528

Yu Li

https://orcid.org/0000-0003-4287-6759 Xichun Wang

https://orcid.org/0000-0003-3801-5753 Jinchun Li

https://orcid.org/0000-0002-8481-9958

Jinjie Wu

https://orcid.org/0000-0001-9706-0808

Submitted Feb 13, 2020; Revised May 13, 2020; Accepted May 29, 2020
Objective: Glucose transporter 9 (GLUT9) is a uric acid transporter that is associated with uric absorption in mice and humans; but it is unknown whether GLUT9 involves in chicken uric acid regulation. This experiment aimed to investigate the chicken GLUT9 expression and serum uric acid (SUA) level.

Methods: Sixty chickens were divided into 4 groups $(n=15)$ : a control group $(\mathrm{NC})$; a sulfonamide-treated group (SD) supplemented with sulfamonomethoxine sodium via drinking water $(8 \mathrm{mg} / \mathrm{L})$; a fishmeal group (FM) supplemented with $16 \%$ fishmeal in diet; and a uric acid-injection group (IU), where uric acid $(250 \mathrm{mg} / \mathrm{kg})$ was intraperitoneally injected once a day. The serum was collected weekly to detect the SUA level. Liver, kidney, jejunum, and ileum tissues were collected to detect the GLUT9 mRNA and protein expression. Results: The results showed in the SD and IU groups, the SUA level increased and GLUT9 expression increased in the liver, but decreased in the kidney, jejunum, and ileum. In the FM group, the SUA level decreased slightly and GLUT9 expression increased in the kidney, but decreased in the liver, jejunum, and ileum. Correlation analysis revealed that liver GLUT9 expression correlated positively, and renal GLUT9 expression correlated negatively with the SUA level.

Conclusion: These results demonstrate that there may be a feedback regulation of GLUT9 in the chicken liver and kidney to maintain the SUA balance; however, the underlying mechanism needs to be investigated in future studies.

Keywords: Chicken; Layer; Uric Acid; Glucose Transporter 9

\section{INTRODUCTION}

Uric acid (UA) is the final product of exogenous and endogenous purine metabolism, and its over-generation or under-excretion may lead to hyperuricemia [1]. Normally, serum uric acid (SUA) levels are balanced between liver production and renal and intestinal excretion [2]. Approximately $90 \%$ of the SUA is filtered in the glomerulus, and then reabsorbed in the renal tubules. However, UA is a polar molecule and, thus, cannot freely pass through the cell membrane. Therefore, the process of UA reabsorption depends on ion channels. A genome-wide association study has revealed numerous genes (encoding for UA transporters) that are associated with hyperuricemia and gout [3].

Glucose transporter 9 (GLUT9) was originally thought to a glucose transport. However, a previous study showed that the inactivation of glucose transporter 2 in the liver completely blocked glucose uptake by cells and GLUT9 was still highly expressed, indicating that the main role of GLUT9 is not glucose transportation [4]. Later, Vitart et al [5] used Xenopus oocytes to express splice variants of the human solute carrier family 2 member 9 (SLC2A9) gene and discovered that human GLUT9 (hGLUT9) is a transport protein for 
UA. Subsequently, some studies have demonstrated that hGLUT9 is closely related to UA metabolism $[6,7]$, it is a high-capacity/high-affinity UA transporter, and it is the only member of the GLUT family that transports UA $[8,9]$. The rate of UA transport is 45 - to 60 -fold greater than that of glucose. Therefore, GLUT9 may be a common transporter for both glucose and UA. Furthermore, in mouse, GLUT9 expression is also related to the SUA level, and high GLUT9 expression may cause hyperuricemia by increasing UA reabsorption in mouse kidneys [6]. Research has shown that GLUT9 is mainly expressed in the liver, kidney and the intestine of mice and humans $[10,11]$, and it plays a very important role in UA regulation in mice and humans. In mice, liver GLUT9 helps absorb blood urea into hepatocytes for uricasemediated degradation; renal tubule GLUT9 helps reabsorb UA from the urine back into the blood circulation [12]. Thus, mouse GLUT9 (mGLUT9) plays a major role in UA homeostasis through its dual functions in the kidney and liver [13, 14]. However, human liver lacks uricase [15] and therefore GLUT9 expression may differ from that in mouse. Current research on GLUT9 mainly involves human and mouse kidney UA-transport systems $[16,17]$, whereas relevant studies in the human liver and intestine are limited. Due to the lack of uricase, chicken UA metabolism may be similar to that in humans; therefore, chicken may be an ideal model for functional studies of the human UA transporter.

A phylogenetic analysis of the chicken GLUT9 (cGLUT9) amino acid sequence revealed that it is identical to that of the hGLUT9 gene, and that GLUT9 is expressed in the liver of chicken, is related to glucose metabolism, and is regulated by insulin $[18,19]$. However, substrate specificity of cGLUT9 remains unknown. Studies of whether cGLUT9 is involved in regulating chicken UA levels have not been conducted. Some research suggest that high-protein diets [20], sulfamonomethoxine [21], and intraperitoneal UA injections can increase the SUA level [22]. This study aims to identify the expression of cGLUT9 in the liver, kidney, jejunum and ileum of the chicken, and determine its relationship with the SUA level.

\section{MATERIALS AND METHODS}

\section{Experimental design}

In this experiment, sixty female ISA Brown laying hen chicks (twenty days old) were randomly divided into four groups (n $=15$ per group). The control group (NC) was fed the basal diet; the sulfonamide group (SD) was fed the basal diet, with soluble sulfamonomethoxine sodium powder added to the drinking water $(8 \mathrm{mg} / \mathrm{L})$. Hengxin Pharmaceutical, Shijiazhuang, China); the fishmeal group (FM) was fed the basal diet supplemented with $16 \%$ fishmeal (crude protein, $25.6 \%$ ); and the UA-injected group (IU) was fed the basal diet and administered UA (250 mg/kg, Sigma, St. Louis, MO, USA) by intraperitoneal injection (UA suspended in 0.5\% carboxymethyl cellulose-Na solution) (Solarbio, Shanghai, China) once a day. The experiment lasted three weeks, and all the chickens were reared in cages and allowed ad libitum consumption of feed and water. The room temperature was $25^{\circ} \mathrm{C}$ to $30^{\circ} \mathrm{C}$ and $12 \mathrm{~h}$ light. The diet compositions were based on the recommended requirements of the National Research Council (1994) (Table 1). After fasting for $12 \mathrm{~h}$, the chickens blood samples were collected from their jugular vein once a week; the blood was allowed to clot for approximately $30 \mathrm{~min}$ at $37^{\circ} \mathrm{C}$, and then centrifuged at $3,500 \times \mathrm{g}$ for $10 \mathrm{~min}$ to obtain the serum. The collected serum was stored at $-20^{\circ} \mathrm{C}$. At the end of the experiment (41 days of age), six chickens from each group were euthanized by decapitation. Liver, kidney, jejunum, and ileum tissues were collected and stored for the subsequent analyses. This study protocol was approved by the Animal Care and Ethics Committee of Anhui Agricultural University (ZXD-P2017625).

\section{Determination of the serum uric acid Level}

The SUA level was measured (UA enzymatic method) using an automated biochemical analyzer [23] (BS-220; Mindray, Shenzhen, China) according to the manufacturer's instructions .

Table 1. Dietary ingredients and main nutritional composition

\begin{tabular}{|c|c|}
\hline Items & \\
\hline \multicolumn{2}{|l|}{ Ingredient (\%) } \\
\hline Corn & 55 \\
\hline Bran & 5 \\
\hline Soybean meal & 20 \\
\hline Cotton wool & 3 \\
\hline Corn protein flour & 5 \\
\hline Soybean oil & 1 \\
\hline DDGS & 5 \\
\hline Calcium powder & 1 \\
\hline Premix $^{1)}$ & 5 \\
\hline Total & 100 \\
\hline \multicolumn{2}{|c|}{ Main nutritional composition } \\
\hline Crude protein (\%) & 18.15 \\
\hline Calcium (\%) & 1.21 \\
\hline Phosphorus (\%) & 0.51 \\
\hline Methionine (\%) & 0.32 \\
\hline Lysine $(\%)$ & 0.76 \\
\hline Total energy (MJ/kg) & 11.55 \\
\hline \multicolumn{2}{|c|}{$\begin{array}{l}\text { DDGS, dried distillers grains with solubles. } \\
\text { 1) Premix (Hualuo } 5 \% \text { premix for layer during brood period, Zhongmu, } \\
\text { China). Premix supplied per kilogram of diet: vitamin A (retinyl acetate) } \\
48.2 \text { to } 99.8 \mathrm{mg} \text {, vitamin } \mathrm{E} \text { (dl-a-tocopheryl acetate) } \geq 350 \mathrm{mg} \text {, vitamin } \mathrm{B}_{1} \\
\geq 50 \mathrm{mg} \text {, vitamin } \mathrm{B} 6 \geq 80 \mathrm{mg} \text {, nicotinamide } \geq 550 \mathrm{mg} \text {, pantothenic acid } \\
280 \mathrm{mg} \text {, zinc } 1,000 \text { to } 3,000 \mathrm{mg} \text {, copper } 5 \text { to } 700 \mathrm{mg} \text {, manganese } 1,000 \\
\text { to } 3,000 \mathrm{mg} \text {, selenium } 2 \text { to } 10 \mathrm{mg} \text {, total phosphorus } \geq 2.6 \% \text {, folic acid } \\
\geq 16 \mathrm{mg} \text {, vitamin } \mathrm{D}_{3} \geq 5 \text { to } 90,000 \mathrm{IU} \text {, vitamin } \mathrm{K}_{3} 40 \text { to } 75 \mathrm{mg} \text {, vitamin } \mathrm{B}_{2} \\
\geq 150 \mathrm{mg} \text {, vitamin } \mathrm{B}_{12} \geq 0.3 \mathrm{mg} \text {, biotin } \geq 1.8 \mathrm{mg} \text {, iron } 1,600 \text { to } 15,000 \mathrm{mg} \text {, } \\
\text { choline chloride } \geq 7,000 \mathrm{mg} \text {, iodine } 6 \text { to } 100 \mathrm{mg} \text {, calcium } 16 \% \text { to } 22 \% \text {, } \\
\text { sodium chloride } 5 \% \text { to } 9 \% \text {. }\end{array}$} \\
\hline
\end{tabular}


Detection of GLUT9 mRNA expression by quantitative real-time polymerase chain reaction

Total RNA from the liver, kidney, jejunum and ileum (100 $\mathrm{mg}$ ) was extracted based on a previously published study [24]. Tissues were ground in liquid nitrogen and homogenized in $1 \mathrm{~mL}$ of Trizol (Thermo Scientific, Waltham, MA, USA). The extracted RNA concentrations were determined on a NanoVue Plus instrument (Thermo Scientific, USA). Then, reverse transcription of $500 \mathrm{ng}$ of total RNA was performed, followed by quantitative polymerase chain reaction (qPCR) at $95^{\circ} \mathrm{C} 2 \mathrm{~min}, 40$ cycles at $60^{\circ} \mathrm{C}$ for $1 \mathrm{~min}, 60^{\circ} \mathrm{C}$ for $30 \mathrm{~s}, 60$ to $95^{\circ} \mathrm{C}$ in $0.2^{\circ} \mathrm{C} / \mathrm{s}$, and $10 \mathrm{~s}$ at $20^{\circ} \mathrm{C}$. The sequences of the primers used for the qPCR analysis of chicken GLUT9 (SLC2A9) expression are shown in Table 2. The experiment was replicated three times. The relative expression of mRNA was analyzed using the $2^{-\Delta \Delta C t}$ method [25].

Detection of GLUT9 protein expression by western blot Total protein was extracted from the liver, kidney, jejunum and ileum (100 mg) of fowl using $1 \mathrm{~mL}$ of RIPA cell lysate (Biosharp, Shanghai, China), $10 \mu \mathrm{L}$ of protease inhibitor (Solarbio, China), and $20 \mu \mathrm{L}$ of phosphatase inhibitor (Solarbio, China), and the resulting mixture was homogenized for $2 \mathrm{~min}$. The cells were lysed at $4^{\circ} \mathrm{C}$ for $20 \mathrm{~min}$. The lysates were then centrifuged at $12,000 \times \mathrm{g}$ for $10 \mathrm{~min}$ at $4^{\circ} \mathrm{C}$. The supernatant was aspirated and stored at $-80^{\circ} \mathrm{C}$. The protein concentration was determined using the BCA method [26] (Biosharp, China).

For western blotting, $50 \mu \mathrm{g}$ of the treated sample was electrophoresed at $80 \mathrm{~V}$ for $40 \mathrm{~min}$ on a $5 \%$ sodium dodecyl sulfate (SDS) -polyacrylamide stacking gel, followed by electrophoresis at $120 \mathrm{~V}$ for $80 \mathrm{~min}$ on a 10\% SDS-polyacrylamide running gel. The proteins were electrophoretically transferred on to a polyvinylidene fluoride membrane at $120 \mathrm{~V}$ for $26 \mathrm{~min}$. The rabbit anti-GLUT9 antibody (diluted 1:1,000; Novus, Littleton, CO, USA) and a goat anti-rabbit immunoglobulin G (IgG) secondary antibody (diluted 1:5,000; ImmunoWay, Plano, TX, USA) were used. The proteins were visualized using a Western Blot Detection Kit (Advansta, Menlo Park, CA, USA). The density of the bands was analyzed using the Image Pro Plus software version 6.0 [27] (Media Cybernetics, Washington, MD, USA), and the protein expression was normalized to $\beta$-actin band.

\section{Detection of GLUT9 protein expression by immunohistochemistry}

The tissues (liver, kidney, jejunum, and ileum) were fixed in $4 \%$ paraformaldehyde, paraffin-embedded, and cut into $5 \mu \mathrm{m}$ thick sections. Next, the sections were deparaffinized and dehydrated, and then rinsed three times with phosphate-buffered saline (PBS). Subsequently, 3\% hydrogen peroxide was added dropwise to the sections for 25 min to block the endogenous peroxidase activity. The sections were blocked with bovine serum albumin (5\%) at room temperature for $25 \mathrm{~min}$ in the dark and incubated overnight at $4^{\circ} \mathrm{C}$ with diluted anti-GLUT9 polyclonal antibody (1:400; Novus, USA), as described by Liu et al [28]. After $12 \mathrm{~h}$, the sections were washed three times with PBS, and then a goat anti-rabbit IgG secondary antibody (diluted 1:5,000; ImmunoWay, USA) was added dropwise to it. After incubation at $37^{\circ} \mathrm{C}$ for $30 \mathrm{~min}$, the sections were washed again three times with PBS. Coloration was performed with DAB (Zsgb Biotechnology, Beijing, China) for three min, and then the sections were washed with distilled water, stained with hematoxylin, dehydrated, and mounted with a neutral gum. Finally, the immunolabeled sections were observed under a light microscope (Olympus CX31, Tokyo, Japan) and photographs were recorded. Integrated optical density (IOD) for each section was measured using the Image-Pro Plus version 6.0 [27] (Media Cybernetics, USA).

\section{Statistical analysis}

Data are expressed as mean \pm standard error. Differences in SUA as well as GLUT9 levels between treatment groups and NC group were analyzed by one-way analysis of variance using LSD and Duncan's multiple comparison post test using IBM SPSS Statistics [29]. Statistical significance is defined when $\mathrm{p}$ values are less than 0.05 . The correlation analysis was conducted to explore the relationship between SUA and GLUT9 mRNA expression by Pearson's correlation coefficients. Graphs and scatter plots were generated using GraphPad Prism [30].

\section{RESULTS}

Serum uric acid level of chickens

As shown in Table 3, on day 7, the SUA level was significantly increased $(\mathrm{p}<0.05)$ in the SD and IU groups compared with

Table 2. Chicken GLUT9 (SLC2A9) primers sequences for quantitative polymerase chain reaction

\begin{tabular}{llcc}
\hline Gene & Primer sequence $\left.\mathbf{( 5}^{\prime} \mathbf{- 3} \mathbf{3}^{\prime}\right)$ & Length (bp) & Accession No. \\
\hline GLUT9-F & GCATCATTCTGCATTGGACC & 119 & XM_420789.5 \\
GLUT9-R & AAGTTGGAGAGCCAGTTGAC & 99 & M_59389.1 \\
$18 S-F$ & CGGCGACGACCCATTCGAAC & & \\
$18 S-R$ & GAATCGAACCCTGATTCCCCGTC & & \\
\hline
\end{tabular}

GLUT9, glucose transporter 9; SLC2A9, solute carrier family 2 member 9. 
Table 3. Serum uric acid level $(\mu \mathrm{mol} / \mathrm{L})$ of chickens in each group (n $=10$ )

\begin{tabular}{lllll}
\hline Groups $^{\text {1) }}$ & \multicolumn{1}{c}{$\mathbf{0 ~ d ~}$} & \multicolumn{1}{c}{$\mathbf{~} \mathbf{d}$} & \multicolumn{1}{c}{$\mathbf{1 4} \mathbf{d}$} & \multicolumn{1}{c}{$\mathbf{2 1} \mathbf{d}$} \\
\hline NC & $111.6 \pm 9.3$ & $125.7 \pm 8.6$ & $123.3 \pm 3.6$ & $115.7 \pm 7.3$ \\
SD & $112.0 \pm 4.1$ & $158.4 \pm 12.6 *$ & $136.9 \pm 11.5$ & $141.7 \pm 19.1$ \\
FM & $110.7 \pm 7$ & $119.1 \pm 9.6$ & $107.7 \pm 8.3$ & $112.9 \pm 7.8$ \\
IU & $114.3 \pm 9.1$ & $160.8 \pm 7.2 *$ & $134.5 \pm 4.1$ & $152.9 \pm 6.1 *$ \\
\hline
\end{tabular}

1) NC, control group; SD, sulfonamide group; FM, fishmeal group; IU, uric-injected group.

${ }^{\star} p<0.05$ vs NC group (one-way analysis of variance).

that in the NC group. On day 14, the SUA level was higher in the SD and IU groups than in the NC group, but not statistically significant. On day 21 , the SUA level was increased $(\mathrm{p}=0.119)$ in the SD group and significantly increased $(\mathrm{p}<$ $0.05)$ in the IU group compared with the NC group. The SUA level in the FM group was decreased throughout the experimental period compared with the NC group, but there was no significant difference compared with the NC group.

GLUT9 mRNA and protein expression in the liver, kidney, jejunum, and ileum of normal chickens The mRNA and protein expression of GLUT9 was quantified in four major tissues of chicken. As shown in Figure 1, the GLUT9 mRNA and protein in normal chickens is mainly expressed in the liver, followed by the jejunum, then the ileum, and least in the kidney.

GLUT9 mRNA and protein expression in the liver, kidney, jejunum and ileum of chickens in each group by qPCR and western blot

The qPCR results were shown in Figure 2. Compared with the NC group, liver GLUT9 mRNA expression of the FM group was decreased, but increased in the SD and IU groups (Figure 2A). Conversely, renal GLUT9 mRNA expression was increased in the FM group $(\mathrm{p}<0.01)$, but decreased in the SD and IU groups (Figure $2 \mathrm{~B}$ ). The jejunum and ileum GLUT9 mRNA expression were decreased in the FM, SD, and IU groups (Figures 2C, D), compared with that in the NC group.

The western blot results as shown in Figure 3, reiterated the qPCR results. Compared with the NC group, the liver GLUT9 protein expression was decreased in the FM group, but increased in the SD and IU groups (Figure 3A). On the other hand, renal GLUT9 protein expression was increased in the FM group, but decreased in the SD and IU groups (Figure 3B). The jejunum and ileum GLUT9 protein expression were decreased in the FM, SD, and IU groups (Figures 3C, D), compared with that in the $\mathrm{NC}$ group.

GLUT9 protein expression in the liver, kidney, jejunum and ileum of chickens in each group by

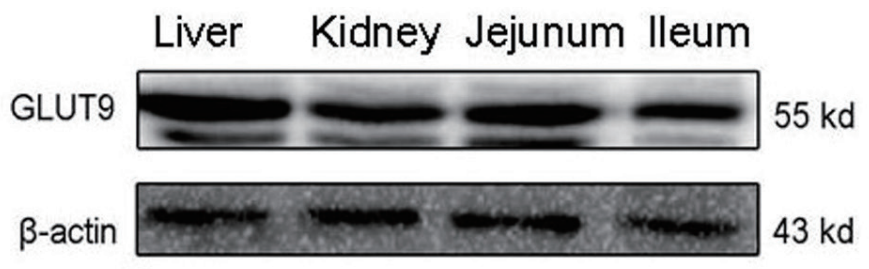

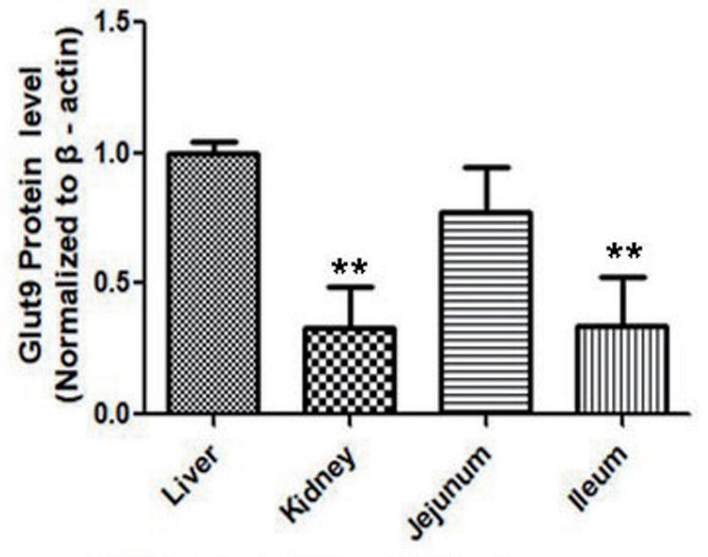

Glut9 protein tissue distribution

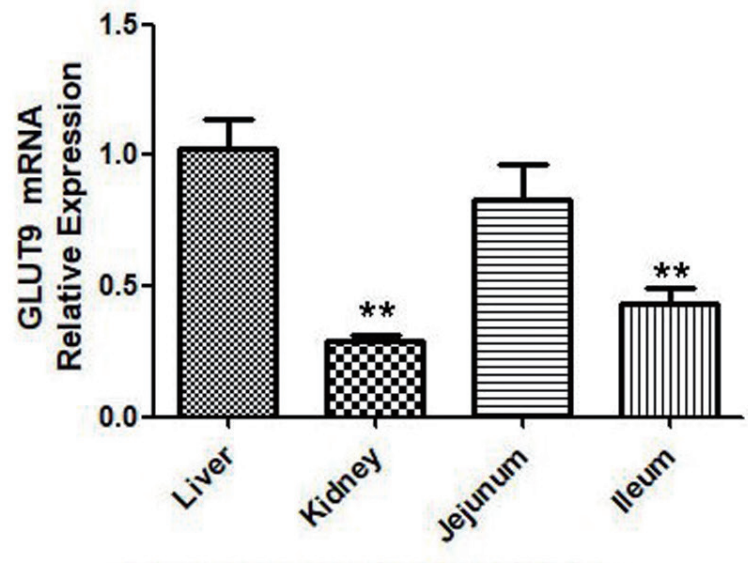

Glut9 mRNA tissue distribution

Figure 1. GLUT9 mRNA and protein expression in the liver, kidney, jejunum and ileum of normal chickens, as determined by qPCR and western blot $(n=6)$. The GLUT9 mRNA and protein expression levels in the kidney, jejunum and ileum were compared with those in the liver. GLUT9, glucose transporter 9; qPCR, quantitative polymerase chain reaction; NC, control group; SD, sulfonamide group; FM, fishmeal group; IU, uric-injected group. ** Indicates $p<0.01$ compared with the NC group. 

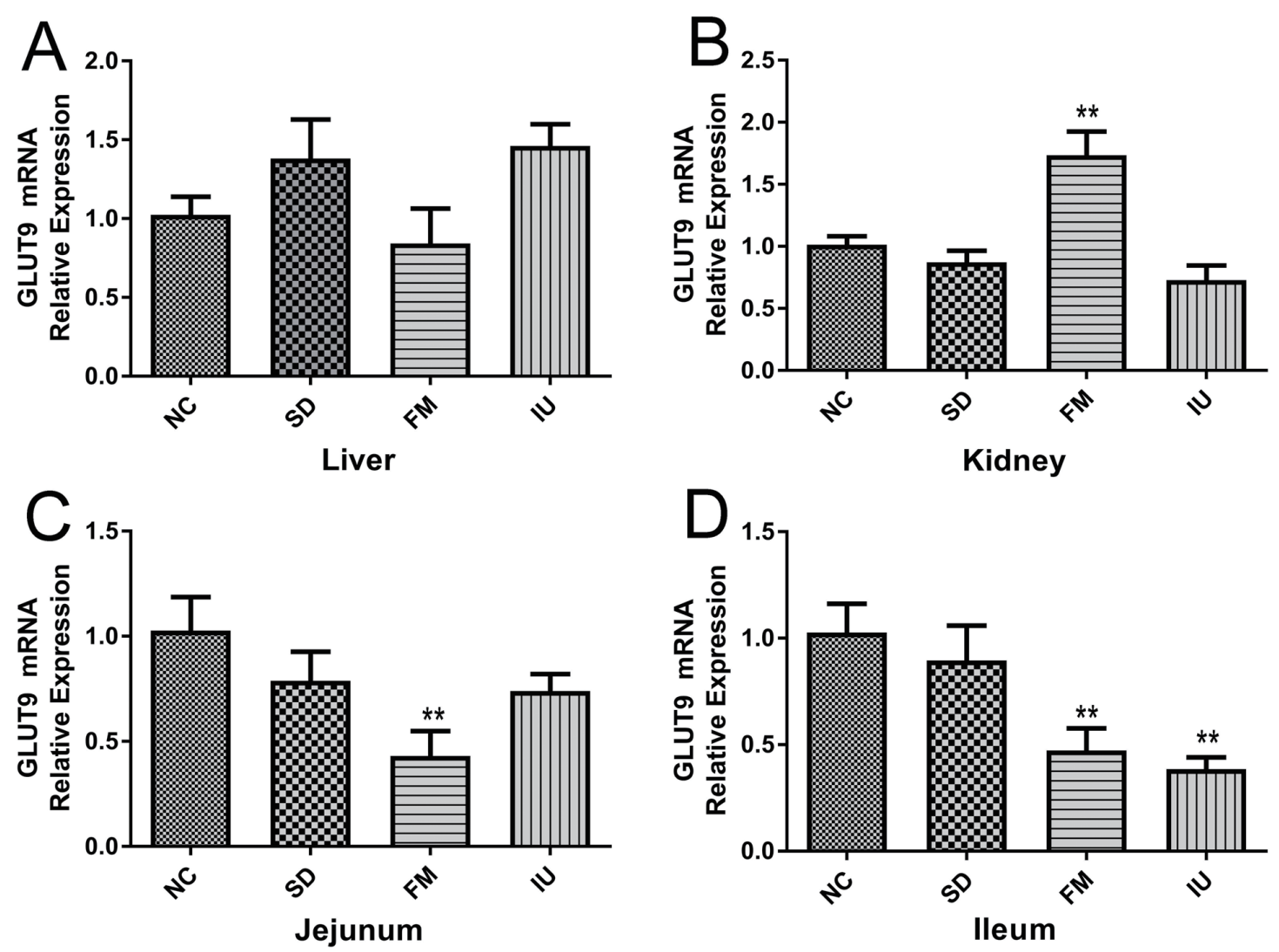

Figure 2. GLUT9 mRNA expression in the liver, kidney, jejunum and ileum of chickens in each group, as determined by qPCR ( $\mathrm{n}=6$ ). GLUT9, glucose transporter 9; qPCR, quantitative polymerase chain reaction; NC, control group; SD, sulfonamide group; FM, fishmeal group; IU, uric-injected group. ${ }^{\star *} p<0.01$ vs NC group (one-way analysis of variance).

immunohistochemistry

The immunohistochemistry results are shown in Figure 4 and Table 4. Compared with the NC group, liver GLUT9 protein expression was decreased in the FM group $(\mathrm{p}<0.01)$, but increased in the SD and IU groups. Conversely, renal GLUT9 protein expression was increased in the FM group $(\mathrm{p}<0.01)$, but decreased in the SD and IU groups. GLUT9 protein expression in the jejunum and ileum tissues was decreased in all the FM, SD, and IU groups, compared with that in the NC group $(\mathrm{p}<0.01)$.

\section{Correlation between the serum uric acid level and GLUT9 mRNA relative expression}

Based on the results described above, a correlation analysis was performed to examine the relationship between the SUA level and GLUT9 expression in the liver and kidney. The results found that the SUA level was positively related to the GLUT9 mRNA expression in the liver (Figure 5A), with a correlation coefficient of 0.592 . However, in the kidney, the SUA level was negatively correlated with GLUT9 mRNA expression (Figure 5B), with a correlation coefficient of -0.622 . Furthermore, there were no obvious correlation between the SUA level and GLUT9 mRNA expression in the jejunum and ileum.

\section{DISCUSSION}

The SUA level reflects the balance between UA production and excretion. The production of UA depends on the intake of dietary protein and the breakdown of endogenous purines by xanthine oxidase. The kidneys are the major site of UA excretion and the small intestines are the secondary sites [31]. Excessive UA production or low excretion can increase the SUA levels, leading to hyperuricemia. Approximately $90 \%$ of hyperuricemia is associated with reduced UA excretion and only $10 \%$ is caused by increased UA production [32]. In the present study, intraperitoneal UA injection was used to increase the SUA level, which is consistent with the results of a previous study [22]. Supply of sulfamonomethoxine in drinking water also increased the SUA level, which may be caused by sulfonamide-dependent blocking of the renal tubules and reduced UA excretion [21]. A previous study demonstrated that high-protein diets can increase the SUA level in chicken [20]. In the present study, supplementary fishmeal in the diet was used to increase the dietary protein level, but it did not increase the chicken SUA level, 

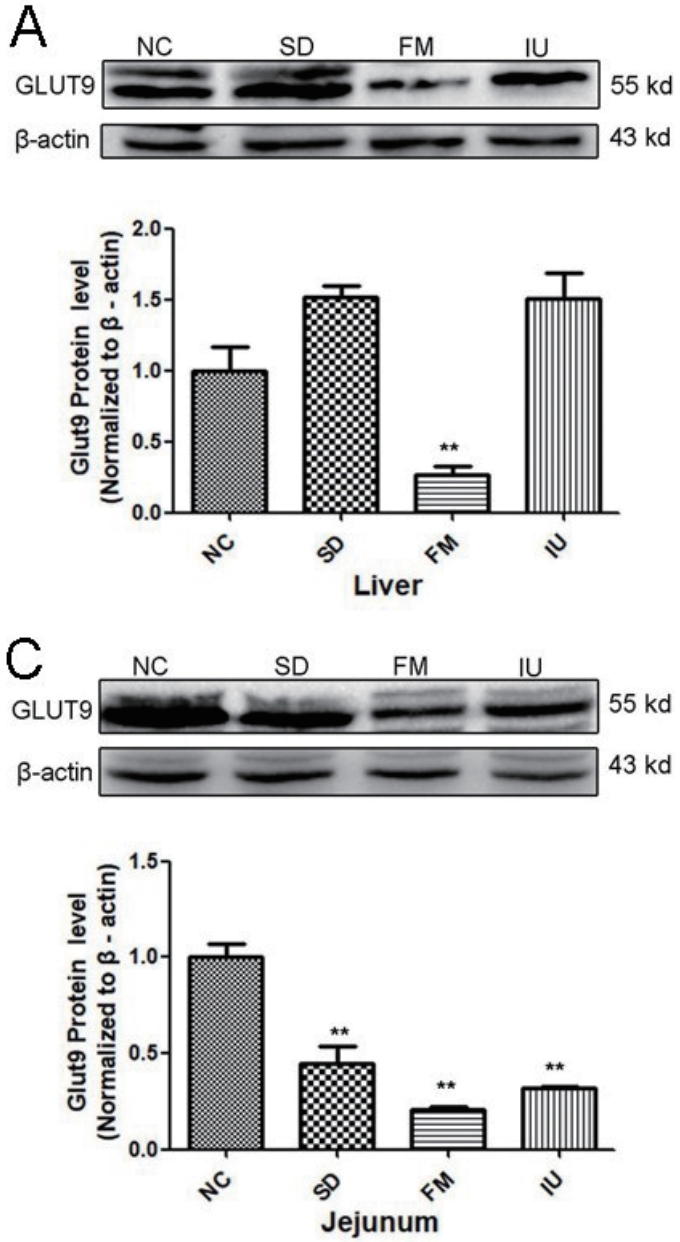
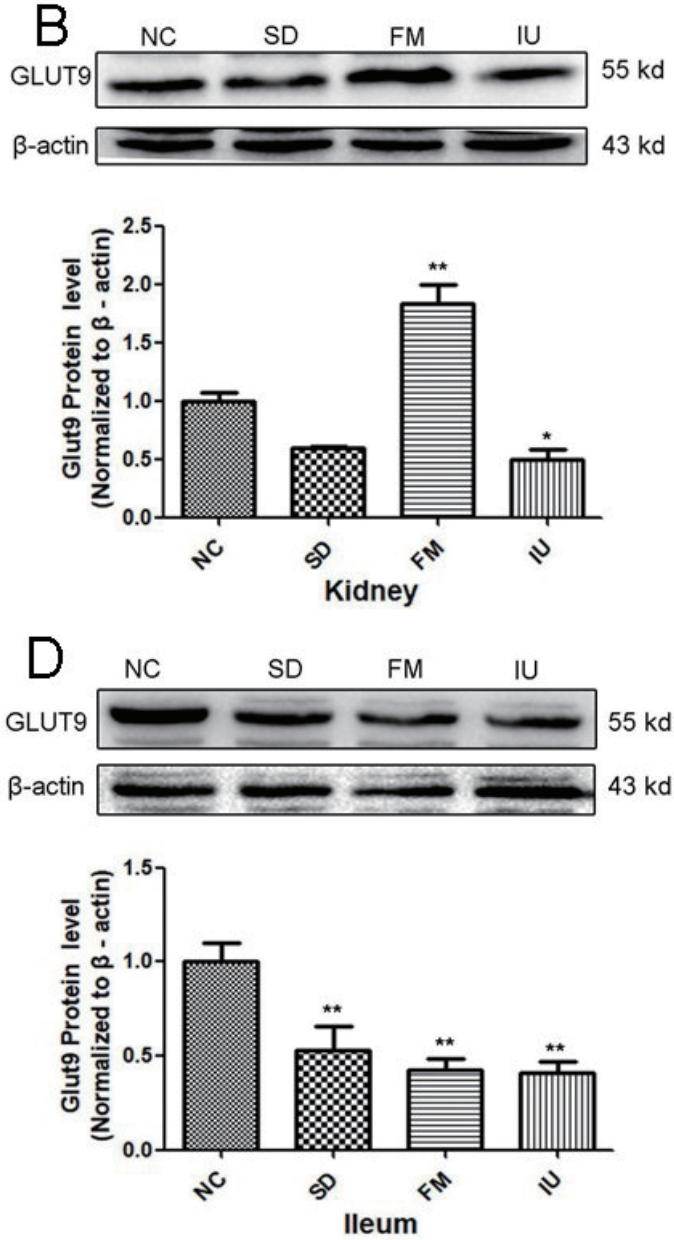

Figure 3. GLUT9 protein expression in the liver, kidney, jejunum and ileum of chickens in each group, as determined by western blot ( $\mathrm{n}=6$ ). GLUT9, glucose transporter 9; NC, control group; SD, sulfonamide group; FM, fishmeal group; IU, uric-injected group. * $p<0.05$ and ${ }^{\star *} p<0.01$ vs NC group (one-way analysis of variance).

thus, further study is needed in this regard.

Similar to the findings of a previous study in mice [11], the results of the present study show that the cGLUT9 mRNA and protein is mainly expressed in the liver, followed by the jejunum, whereas the ileum and the kidney show less expression. The immunohistochemistry results indicate that the pattern of GLUT9 protein expression in the chicken liver is consistent with that in the humans and the mice; that is, it is mainly expressed in hepatocytes. However, GLUT9 expression in chicken renal tubules differ from that in humans and mice. mGLUT9 is mainly expressed in basolateral membrane of the renal proximal tubules and is weakly expressed in the proximal tubules $[12,14,33]$. The human GLUT9 protein is mainly localized in the basolateral membrane of the proximal tubules $[10,34]$. The immunohistochemistry results of the present study demonstrate that the cGLUT9 protein is expressed both in the renal proximal tubules and distal tubules. The renal tubules are the major site of UA reabsorption, and the differential expression of GLUT9 may reflect dif- ferences in UA reabsorption between human, mouse and chicken. The chicken intestinal GLUT9 protein is abundantly expressed in the jejunum and ileum, and it is mainly located in the apical membrane of intestinal villus cells. In mice, immunofluorescence staining show that the intestinal GLUT9 protein is mainly located in the basolateral and apical membranes of jejunal and ileal villus cells [35]. Therefore, GLUT9 protein expression in the liver, kidney, jejunum and ileum exhibit some similarities and differences between chicken, human and mouse. However, little is known regarding the molecular mechanisms of GLUT9 function in diverse tissues, which merits further study.

In mice, there are two main ways to eliminate SUA: via uricase-dependent degradation in the liver and via secretion by the kidney and intestines, and both the routes require the involvement of GLUT9 [12]. Liver GLUT9 is the main transport protein that transports blood urea into hepatocytes. When liver GLUT9 is specifically inactivated, mice develop severe hyperuricemia. In the present study, the 

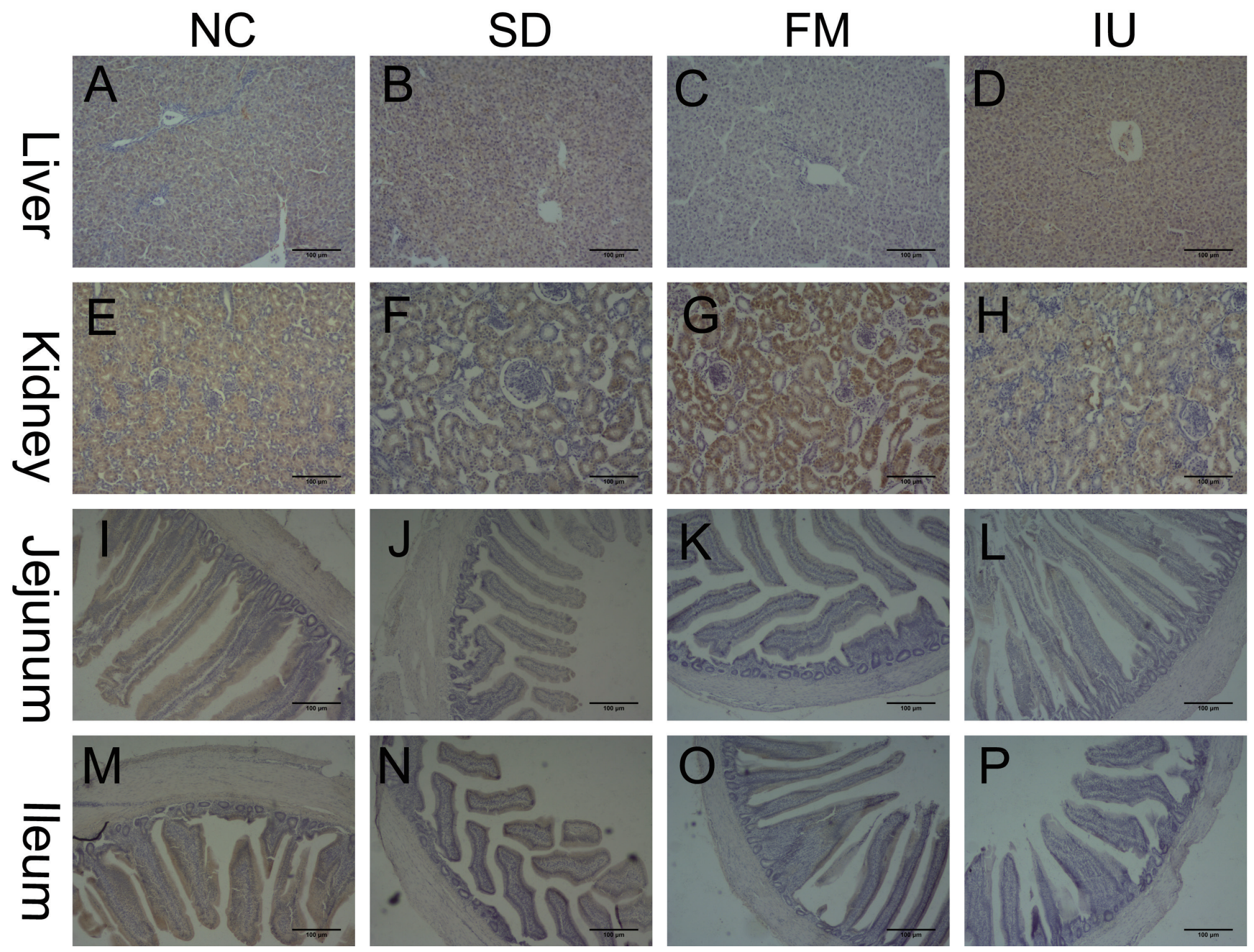

Figure 4. GLUT9 protein expression in the liver, kidney, jejunum and ileum of chickens in each group, as determined by immunohistochemistry (n = 6). Scale bars: $100 \mu \mathrm{m}$. GLUT9, glucose transporter 9; NC, control group; SD, sulfonamide group; FM, fishmeal group; IU, uric-injected group.

SUA level was increased in the SD and IU groups, which may be associated with the increase in liver GLUT9 expression and decrease in renal GLUT9 expression. In the FM group, the SUA level was decreased slightly, and GLUT9 expression was increased in the kidney and decreased in the liver. A similar result has been reported by Nagura et al [36], who found that the SUA level in 5/6 nephrectomized mice is increased slightly and renal GLUT9 gene expression is decreased. These findings suggest that there may be a complex regulatory action mode between GLUT9 expression and SUA level. The results of the present study show that liver GLUT9 mRNA and protein expression in chicken correlated positively with the SUA level; while renal GLUT9 mRNA and protein negatively correlate with the SUA level. Thus, we hypothesize that feedback regulation of GLUT9 maintains the SUA balance in the chicken liver and kidneys. When the SUA level was reduced, GLUT9 expression was decreased in the liver, which in turn decreased SUA reabsorp-

Table 4. Average optical density values of glucose transporter 9 protein in the liver, kidney, jejunum and ileum of chickens in each group by immunohistochemistry $(n=6)$

\begin{tabular}{lllll}
\hline Groups $^{1)}$ & \multicolumn{1}{c}{ Liver } & Kidney & Jejunum & Ileum \\
\hline NC & $0.046 \pm 0.0013$ & $0.039 \pm 0.0009$ & $0.057 \pm 0.0021$ & $0.067 \pm 0.0025$ \\
SD & $0.051 \pm 0.0052$ & $0.034 \pm 0.0011$ & $0.039 \pm 0.0022^{\star \star}$ & $0.053 \pm 0.001^{\star \star}$ \\
FM & $0.019 \pm 0.001^{\star \star}$ & $0.058 \pm 0.0048^{\star \star}$ & $0.018 \pm 0.0008^{\star \star}$ & $0.023 \pm 0.0022^{\star \star}$ \\
IU & $0.050 \pm 0.005$ & $0.027 \pm 0.0035^{\star}$ & $0.02 \pm 0.0009^{\star \star}$ & $0.022 \pm 0.0013^{\star \star}$ \\
\hline
\end{tabular}

1) NC, control group; SD, sulfonamide group; FM, fishmeal group; IU, uric-injected group.

${ }^{*} p<0.05$ and ${ }^{* \star} p<0.01$ vs NC group (one-way analysis of variance). 

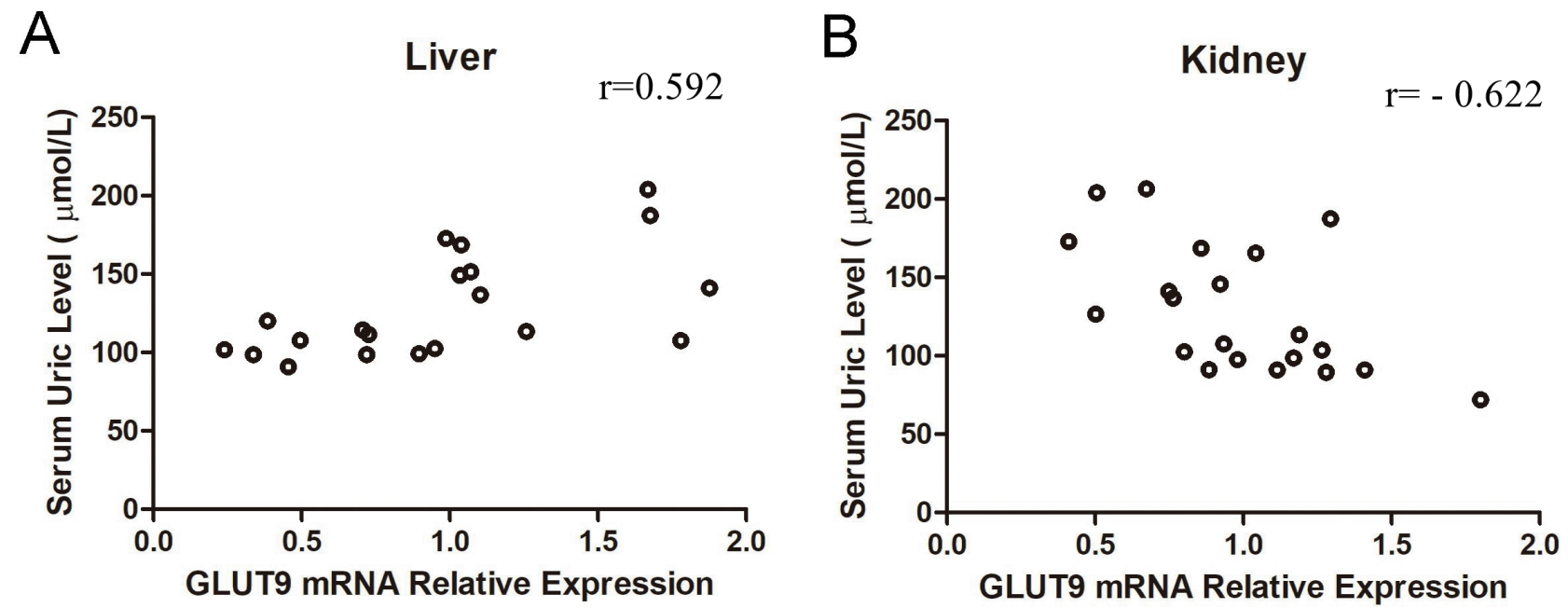

Figure 5. Correlation between the serum uric acid level and GLUT9 mRNA relative expression. GLUT9, glucose transporter 9.

tion in the liver. Simultaneously, GLUT9 protein expression was increased in the kidneys and UA reabsorption was increased in the renal tubules to raise the SUA level. Accordingly, when the SUA level was elevated, liver GLUT9 expression was increased and renal expression was decreased to lower the SUA level.

In mice, most UA excretion occurs in the jejunum and ileum and intestinal GLUT9 functions to regulate UA clearance; hyperuricemia occurs in intestinal GLUT9-deficient mice [35]. However, in the present study, we found that GLUT9 mRNA and protein expression in the jejunum and ileum of chicken was not related with the changes in the SUA level, warranting further investigation into the mechanism of GLUT9 function in chicken intestines.

In summary, the liver GLUT9 expression correlated positively with the SUA level, while renal GLUT9 expression correlated negatively with the SUA level. The GLUT9 expression in the jejunum and ileum does not seem to be significantly associated with the SUA level. Thus, there may be a feedback regulation of GLUT9 in the chicken liver and kidney that maintains the SUA balance, but the underlying mechanism is still unknown and requires further studies.

\section{CONFLICT OF INTEREST}

We certify that there is no conflict of interest with any financial organization regarding the material discussed in the manuscript.

\section{ACKNOWLEDGMENTS}

We are grateful to the animal hospital of Anhui Agricultural University. We wish to thank anonymous reviewers for their kind advice.
This work was supported by the National Key Research and Development Program of China (No.2016YFD0501205) and the Key Research and Development Program of Anhui Province of China (No.1804a07020135), this manuscript was designed, edited and revised by the funder J.J. W.

\section{REFERENCES}

1. Yamauchi T, Ueda T. Primary hyperuricemia due to decreased renal uric acid excretion. Nihon Rinsho 2008;66:679-81.

2. El Ridi R, Tallima $H$. Physiological functions and pathogenic potential of uric acid: a review. J Adv Res 2017;8:487-93. https:// doi.org/10.1016/j.jare.2017.03.003

3. Xu L, Shi Y, Zhuang S, Liu N. Recent advances on uric acid transporters. Oncotarget 2017;8:100852-62. https://doi.org/ 10.18632/oncotarget.20135

4. Mobasheri A, Dobson H, Mason SL, et al. Expression of the GLUT1 and GLUT9 facilitative glucose transporters in embryonic chondroblasts and mature chondrocytes in ovine articular cartilage. Cell Biol Int 2005;29:249-60. https://doi. org/10.1016/j.cellbi.2004.11.024

5. Vitart V, Rudan I, Hayward C, et al. SLC2A9 is a newly identified urate transporter influencing serum urate concentration, urate excretion and gout. Nat Genet 2008;40:437-42. https:// doi.org/10.1038/ng.106

6. Kimura T, Amonpatumrat S, Tsukada A, et al. Increased expression of SLC2A9 decreases urate excretion from the kidney. Nucleosides Nucleotides Nucleic Acids 2011;30:1295301. https://doi.org/10.1080/15257770.2011.628354

7. Ruiz A, Gautschi I, Schild L, Bonny O. Human mutations in SLC2A9 (Glut9) affect transport capacity for urate. Front Physiol 2018;9:476. https://doi.org/10.3389/fphys.2018.00476

8. Mueckler M, Thorens B. The SLC2 (GLUT) family of membrane transporters. Mol Aspects Med 2013;34:121-38. https:// 
doi.org/10.1016/j.mam.2012.07.001

9. Clémençon B, Lüscher BP, Fine M, et al. Expression, purification, and structural insights for the human uric acid transporter, GLUT9, using the Xenopus laevis oocytes system. PLoS One 2014;9:e108852. https://doi.org/10.1371/journal. pone. 0108852

10. Augustin R, Carayannopoulos MO, Dowd LO, Phay JE, Moley JF, Moley KH. Identification and characterization of human glucose transporter-like protein-9 (GLUT9): alternative splicing alters trafficking. J Biol Chem 2004;279:16229-36. https://doi. org/10.1074/jbc.M312226200

11. Bu P, Le Y, Zhang Y, Cheng X. Hormonal and chemical regulation of the Glut9 transporter in mice. J Pharmacol Exp Ther 2017;360:206-14. https://doi.org/10.1124/jpet.116.237040

12.Preitner F, Bonny O, Laverrière A, et al. Glut9 is a major regulator of urate homeostasis and its genetic inactivation induces hyperuricosuria and urate nephropathy. Proc Natl Acad Sci USA 2009;106:15501-6. https://doi.org/10.1073/ pnas.0904411106

13. Matsuo H, Chiba T, Nagamori S, et al. Mutations in glucose transporter 9 gene SLC2A9 cause renal hypouricemia. Am J Hum Genet 2008;83:744-51. https://doi.org/10.1016/j.ajhg. 2008.11.001

14. Bibert S, Hess SK, Firsov D, et al. Mouse GLUT9: evidences for a urate uniporter. Am J Physiol Renal Physiol 2009;297: F612-9. https://doi.org/10.1152/ajprenal.00139.2009

15. Keebaugh AC, Thomas JW. The evolutionary fate of the genes encoding the purine catabolic enzymes in hominoids, birds, and reptiles. Mol Biol Evol 2010;27:1359-69. https://doi.org/ 10.1093/molbev/msq022

16. Auberson M, Stadelmann S, Stoudmann C, et al. SLC2A9 (GLUT9) mediates urate reabsorption in the mouse kidney. Pflugers Arch 2018;470:1739-51. https://doi.org/10.1007/ s00424-018-2190-4

17.Torres RJ, Puig JG. GLUT9 influences uric acid concentration in patients with Lesch-Nyhan disease. Int J Rheum Dis 2018;21:1270-6. https://doi.org/10.1111/1756-185X.13323

18.Zhang W, Sumners LH, Siegel PB, Cline MA, Gilbert ER. Quantity of glucose transporter and appetite-associated factor mRNA in various tissues after insulin injection in chickens selected for low or high body weight. Physiol Genomics 2013; 45:1084-94. https://doi.org/10.1152/physiolgenomics.00102. 2013

19. Bai S, Pan S, Zhang K, et al. Long-term effect of dietary overload lithium on the glucose metabolism in broiler chickens. Environ Toxicol Pharmacol 2017;54:191-8. https://doi.org/10. 1016/j.etap.2017.07.011

20. Guo X, Huang K, Tang J. Clinicopathology of gout in growing layers induced by high calcium and high protein diets. Br Poult Sci 2005;46:641-6. https://doi.org/10.1080/00071660500302 661

21. Mustafa S, Alsughayer A, Elgazzar A, Elassar A, Al Sagheer F.
Effect of sulfa drugs on kidney function and renal scintigraphy. Nephrology 2014;19:210-6. https://doi.org/10.1111/nep.12200

22. Romi MM, Arfian N, Tranggono U, Setyaningsih WAW, Sari DCR. Uric acid causes kidney injury through inducing fibroblast expansion, Endothelin-1 expression, and inflammation. BMC Nephrol 2017;18:326. https://doi.org/10.1186/s12882017-0736-x

23.Zhiqiang C. Studies of determination of calcium, phosphonium and uric acid in urine by automatic biochemical analyzer. J Clin Urol 2006;6:461-3. https://doi.org/10.3969/j.issn.10011420.2006.06.023

24.Zeng Y, Callaghan D, Xiong H, Yang Z, Huang P, Zhang W. Abcg2 deficiency augments oxidative stress and cognitive deficits in Tg-SwDI transgenic mice. J Neurochem 2012;122: 456-69. https://doi.org/10.1111/j.1471-4159.2012.07783.x

25.Livak KJ, Schmittgen TD. Analysis of relative gene expression data using real-time quantitative PCR and the $2^{-\Delta \Delta C T}$ method. Methods 2001;25:402-8. https://doi.org/10.1006/meth.2001. 1262

26.Smith PK, Krohn RI, Hermanson GT, et al. Measurement of protein using bicinchoninic acid. Anal Biochem 1985;150: 76-85. https://doi.org/10.1016/0003-2697(85)90442-7

27. Francisco JS, de Moraes HP, Dias EP. Evaluation of the ImagePro Plus 4.5 software for automatic counting of labeled nuclei by PCNA immunohistochemistry. Braz Oral Res 2004;18: 100-4. https://doi.org/10.1590/S1806-83242004000200002

28.Liu Y, Sun W, Zhang X, Li J, Zhang H. Compound tufuling granules regulate glucose transporter 9 expression in kidney to influence serum uric acid level in hyperuricemia mice. Chin J Integr Med 2015;21:823-9. https://doi.org/10.1007/ s11655-015-2052-2

29. Field A. Discovering statistics using IBM SPSS statistics. 4ed. Thousand Oaks, CA, USA: Sage Publications; 2013.

30. Ghoodjani A. Advanced statistical methods and applications. Iran: Statistica; 2018.

31. Maesaka JK, Fishbane S. Regulation of renal urate excretion: a critical review. Am J Kidney Dis 1998;32:917-33. https://doi. org/10.1016/S0272-6386(98)70067-8

32. Oka Y, Tashiro H, Sirasaki R, et al. Hyperuricemia in hematologic malignancies is caused by an insufficient urinary excretion. Nucleosides Nucleotides Nucleic Acids 2014;33:434-8. https:// doi.org/10.1080/15257770.2013.872274

33. Keembiyehetty C, Augustin R, Carayannopoulos MO, et al. Mouse glucose transporter 9 splice variants are expressed in adult liver and kidney and are up-regulated in diabetes. Mol Endocrinol 2006;20:686-97. https://doi.org/10.1210/me.20050010

34. Anzai N, Ichida K, Jutabha P, et al. Plasma urate level is directly regulated by a voltage-driven urate efflux transporter URATv1 (SLC2A9) in humans. J Biol Chem 2008;283:26834-8. https:// doi.org/10.1074/jbc.C800156200

35. DeBosch BJ, Kluth O, Fujiwara H, Schürmann A, Moley K. 
Early-onset metabolic syndrome in mice lacking the intestinal uric acid transporter SLC2A9. Nat Commun 2014;5:4642. https://doi.org/10.1038/ncomms5642

36. Nagura M, Tamura Y, Kumagai T, Hosoyamada M, Uchida S.
Uric acid metabolism of kidney and intestine in a rat model of chronic kidney disease. Nucleosides Nucleotides Nucleic Acids 2016;35:550-8. https://doi.org/10.1080/15257770.2016. 1163379 